\title{
Electrospray sample deposition for matrix-assisted laser desorption/ionization (MALDI) and atmospheric pressure MALDI mass spectrometry with attomole detection limits
}

\author{
Hui Wei ${ }^{1}$, Kerstin Nolkrantz ${ }^{1}$, David H. Powell ${ }^{3}$, James H. Woods ${ }^{2}$, Mei-Chuan Ko ${ }^{2}$ \\ and Robert T. Kennedy ${ }^{1,2 *}$ \\ ${ }^{1}$ Department of Chemistry, University of Michigan, Ann Arbor, MI, USA \\ ${ }^{2}$ Department of Pharmacology, University of Michigan, Ann Arbor, MI, USA \\ ${ }^{3}$ Department of Chemistry, University of Florida, Gainesville, FL, USA \\ Received 23 February 2004; Revised 23 March 2004; Accepted 23 March 2004
}

\begin{abstract}
Electrospray sample deposition was explored for matrix-assisted laser desorption/ionization timeof-flight mass spectrometry (MALDI-TOFMS). In this method, nanoliter volumes of matrix/analyte mixture were electrosprayed from a high voltage biased $(1-2 \mathrm{kV})$ fused-silica capillary onto a grounded MALDI plate mounted 100-500 $\mu \mathrm{m}$ from the capillary outlet. Electrospray deposition with these conditions produced sample spots 200-300 $\mu \mathrm{m}$ in diameter thus matching the laser spot size. Varying spray voltage and distance resulted in different crystal sizes and volatilization rates for $\alpha$-cyano-4-hydroxycinnamic acid matrix. Best results were obtained when the sample was deposited as wet droplets as opposed to deposition as dried solid. Under 'wet-spray' conditions, 2-4 $\mathrm{mm}$ diameter crystals were formed and detection limits for several neuropeptides were $0.7-25 \mathrm{amol}$. Samples could be pre-concentrated on the plate by spraying continuously and allowing sample to evaporate in a small spot. Sample volumes as large as $580 \mathrm{~nL}$ were deposited yielding a detection limit of $35 \mathrm{pM}$ for neurotensin 1-11. Electrospray sample deposition yielded similar results when using atmospheric pressure-MALDI coupled with a quadrupole ion trap mass spectrometer, except that the sensitivity was $\sim$ seven-fold worse. Copyright (C) 2004 John Wiley \& Sons, Ltd.
\end{abstract}

Matrix-assisted laser desorption/ionization (MALDI) is a powerful ionization method for mass spectrometric (MS) analysis of proteins and peptides. Sample preparation is critical for achieving high sensitivity and reproducibility by MALDI-MS. The most common way to prepare samples for MALDI is the dried-droplet method. ${ }^{1}$ While this method is simple and adequate for many applications, it suffers from poor shot-to-shot and sample-to-sample reproducibility. This problem, which can be partially overcome by use of isotope-labeled internal standards, is attributed to heterogeneous sample distribution and crystal formation within sample spots. The dried-droplet method is also not applicable to analyses where sample is limited and high mass sensitivity is required. The relatively poor mass sensitivity is due to the large mismatch between sample spot size, 1-4 mm, and laser irradiation spot, $50-200 \mu \mathrm{m}$, resulting in only a small fraction of the sample being exposed to the laser for ion generation. This arrangement allows preservation of sample, but is inefficient and results in detection limits (low fmol for peptides) that are worse than that achievable by the mass spectrometer.

*Correspondence to: R. T. Kennedy, Department of Chemistry, University of Michigan, 930 North University Avenue, Ann Arbor, MI 48109-1055, USA.

E-mail: rtkenn@umich.edu

Contract/grant sponsor: NIH; contract/grant number: 38476 .

Contract/grant sponsor: Wenner-Gren Foundations.
Mass sensitivity and reproducibility can be improved if the sample spot size is comparable to the laser spot size., Methods for creating sample spots that match the laser spot size can be classified into two general approaches: (1) use of target plates that confine samples, and (2) controlled application of sample to the surface. Examples of the first approach include use of silicon vials, ${ }^{4}$ hydrophobic plates with hydrophilic sample wells, ${ }^{5}$ and hydrophobic surfaces. ${ }^{6}$ In all of these approaches samples of $250 \mathrm{pL}$ to $1.5 \mu \mathrm{L}$ can be placed on the target, and as solvent evaporates, the sample is confined to a small surface, typically $100-400 \mu \mathrm{m}$ diameter. Such confinement has led to detection limits of $0.3-100 \mathrm{amol}$ and improved reproducibility when compared with drieddroplet sample preparation. ${ }^{4-6}$

Specialized dispensers have also been used to deposit small volumes and thereby create a well-defined sample spot. A microspot sample preparation technique that utilized a capillary tube to deposit $80-150 \mu \mathrm{m}$ diameter spots onto ultraclean plates yielded a limit of detection (LOD) of $45 \mathrm{zmol}$ for substance P by MALDI-MS. ${ }^{7}$ A piezoelectric flow-through microdispenser ${ }^{8}$ has been used to eject droplets with volumes of $60-100 \mathrm{pL}$ collected at the target plate resulting in sample spots $\sim 400 \mu \mathrm{m}$ in diameter and LOD of $100 \mathrm{amol}$ for a $1 \mathrm{nM}$ solution of peptides. Another approach has been to apply an electrical field pulse across the gap between a capillary with flowing sample (actually LC effluent) and the MALDI target. The voltage pulse causes the droplet at the outlet to be pulled 
down to the surface. Application of the pulse at specific times allows controlled deposition of sample. Detection limits of 50 amol were achieved using MALDI-FT-MS for analysis. Continuous deposition from a flowing stream (e.g., a capillary electrophoresis separation) within a vacuum onto a membrane target pre-coated with MALDI matrix ${ }^{10}$ or the sample mixed with matrix ${ }^{11}$ is also a form of confined sample deposition that enables low amol LOD.

In addition to confining samples, samples may be deposited by spraying them onto the MALDI target plate using a heated nebulizer, ${ }^{12}$ heated droplet interface, ${ }^{13}$ aerospray (pneumatic spraying), ${ }^{14}$ or electrospray. ${ }^{15-19}$ Electrospray deposition was shown to yield improved sample uniformity and smaller crystal size ${ }^{15-17}$ leading to improved reproducibility, sensitivity and increased signal intensity. Several applications of electrospray for MALDI sample preparation have been reported, including its use as a method of applying matrix for imaging tissues ${ }^{20}$ and TLC plates ${ }^{21}$ by MALDI-MS.

While electrospray deposition has shown promising performance, it has not been used in a microscale format that may be expected to improve mass detection limits. In this work we utilize electrospray deposition to create sample spot sizes of 200-300 $\mu \mathrm{m}$ in diameter for use with MALDI and APMALDI. The small size allows mass LOD as low as $0.7 \mathrm{amol}$ and concentration LOD as low as $35 \mathrm{pM}$ by MALDI-TOFMS. In addition, the effects of electrospray conditions on the sample preparation are characterized.

\section{EXPERIMENTAL}

\section{Materials}

All organic solvents and water were obtained from Burdick \& Jackson (Muskegon, MI, USA). $\alpha$-Cyano-4-hydroxycinnamic acid (CHCA) and peptide standards were purchased from Sigma (St. Louis, MO, USA). Trifluoroacetic acid (TFA) was obtained from Fisher Scientific (Chicago, IL, USA) and hydrofluoric acid (HF) was supplied by Acros Organics (Morris Plains, NJ, USA). Fused-silica capillary was from Polymicro Technologies (Phoenix, AZ, USA). $\mathrm{C}_{18}$ Ziptips were purchased from Millipore (Billerica, MA, USA).

\section{Electrospray emitter}

The electrospray emitter was made by pulling a fused-silica capillary (50 or $75 \mu \mathrm{m}$ i.d., $360 \mu \mathrm{m}$ o.d.) using a $\mathrm{CO}_{2}$ P-2000 laser puller (Sutter, Novato, CA, USA). The capillary tip was sanded slightly with a porcelain capillary cutter (Alltech Associates, Inc., Deerfield, IL, USA) to obtain a flat end and etched by $50 \%$ aqueous HF for a few seconds. This procedure yielded a tapered capillary with $10-15 \mu \mathrm{m}$ i.d. at the tip.

\section{Motorized XY stage}

A motorized XY stage was assembled in-house by mounting two MicroStage MS25 linear guides (Thomson Industries, Ronkonkoma, NY, USA) on top of each other to create independent $X$ - and $Y$-motions. Each lead screw was connected to a 200 step per revolution stepper motor GBM 42BYG228 (Jameco Electronics, Belmont, CA, USA) to move its axis. With a $2 \mathrm{~mm}$ lead screw pitch, each motor step resolution was $10 \mu \mathrm{m}$. The motors were controlled by a unipolar stepper motor driver WTSMD-M (Weeder Technologies, Ft. Walton Beach, FL, USA). This driver converts high-level commands sent from a computer serial port into motion with appropriate acceleration profiles. The complete system was capable of moving between two spots separated by $4.5 \mathrm{~mm}$ in less than $1 \mathrm{~s}$. Application of the high voltage was controlled by the computer parallel port connected to the power supply. The entire system was operated by a LabVIEW software program (National Instruments, Austin, TX, USA) which controlled the spot motion sequence, dwell time at each spot, and timing of the deposition on the plate. The deposition capillary was mounted in a clamp on a manual XZ-translation stage next to the motorized $X Y$ stage and positioned at the center of the first spot before the automatic sampling was started.

\section{Deposition device}

The system used for electrospray sample deposition consisted of a syringe pump (Harvard Apparatus, So. Natick, MA, USA), a fused-silica capillary with the electrospray emitter mounted on an XZ-translation stage (Newport, Irvine, CA, USA), a MALDI plate mounted on the motorized XY stage, a high voltage power supply (Spellman CZE 1000R, Hauppauge, NY, USA), and an in-house built microscope (200 $\times$ magnification) mounted on another XYZ-translation stage (Newport, Irvine, CA, USA), as depicted in Fig. 1. The tubing connecting the syringe to the emitter was a $5 \mathrm{~cm}$ length of $50 \mu \mathrm{m}$ i.d. fused-silica tubing. This tubing was connected by a microfilter ( $85 \mathrm{~nL}$ dead volume) to the emitter which was also made from $5 \mathrm{~cm}$ of $50 \mu \mathrm{m}$ i.d. tubing. The resulting

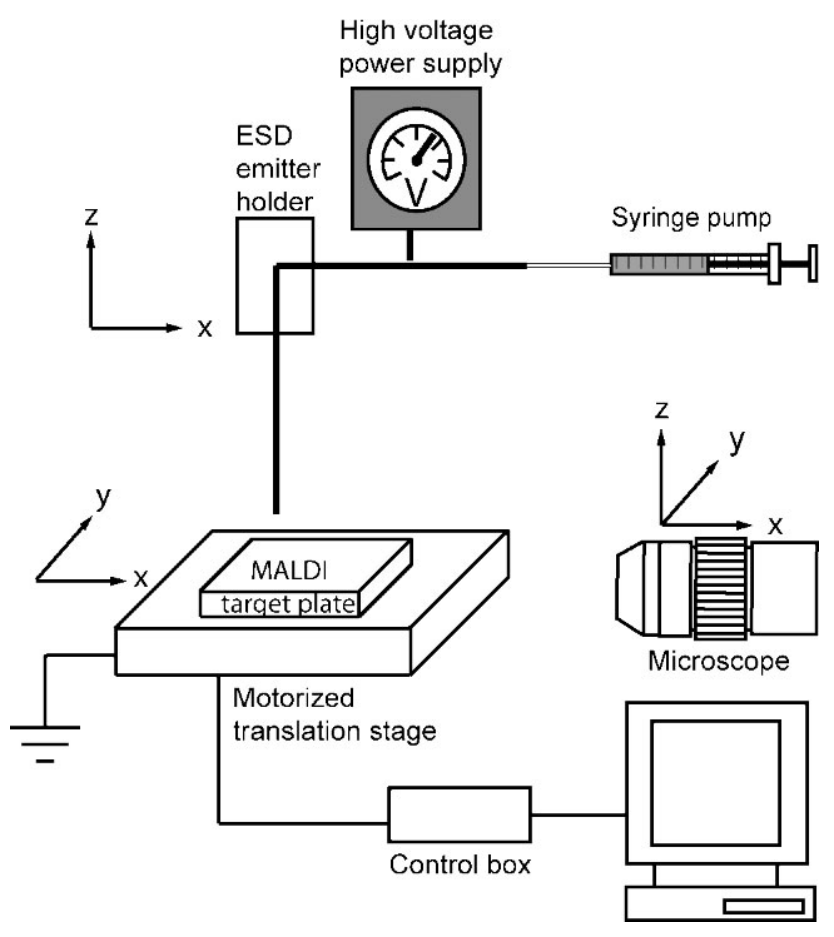

Figure 1. Overview of the electrospray deposition system. The MALDI plate is mounted on a motorized XY-translation stage. High voltage is applied through a syringe needle as the solution is pumped through a capillary system to the electrospray emitter. A home-made microscope is used to observe the spray. 
volume of the entire system was $285 \mathrm{~nL}$. The target plate was mounted on the motorized XY stage.

\section{Mass spectrometry}

A MALDI TOF Spec 2E (Micromass, Milford, MA, USA) mass spectrometer equipped with a delayed extraction source and 337-nm pulsed (4 ns) nitrogen laser was used in the reflectron mode. All mass spectra were obtained in positive ion mode with $20 \mathrm{kV}$ source voltage, $2.2 \mathrm{kV}$ extraction pulse voltage, $19.98 \mathrm{kV}$ extraction voltage, $16 \mathrm{kV}$ focus voltage, and suppression mass of $m / z 500$. The size of the laser spot was $150 \times 250 \mu \mathrm{m}$. The MALDI plate was stainless steel with 96 wells. Mass spectral data were generated by summing 5 to 20 "scans", where each "scan" corresponds to 5 laser shots accumulated into a single spectrum. All experiments were performed using this instrument in positive ion mode unless indicated otherwise.

For AP-MALDI-QIT, a ThermoFinnigan (San Jose, CA, USA) LCQ Deca XP Plus mass spectrometer integrated with a MassTech Inc. (Columbia, MD, USA) AP-MALDI ion source was used with the following settings: automatic gain control off, injection time for MS mode $200 \mathrm{~ms}$ and for $\mathrm{MS}^{2} 300 \mathrm{~ms}$, laser frequency $10 \mathrm{~Hz}(337 \mathrm{~nm})$, capillary temperature $350^{\circ} \mathrm{C}$, spray voltage $2.8 \mathrm{kV}$, tube lens $40 \mathrm{~V}$ and capillary voltage $46 \mathrm{~V}$. The settings of the ion optics were for multipole $1-0.5 \mathrm{~V}$, lens voltage $-33.0 \mathrm{~V}$, multipole $2-11.0 \mathrm{~V}$, multipole $\mathrm{RF}$ $350.0 \mathrm{~V}$ and entrance lens $-64.0 \mathrm{~V}$. No auxiliary or spray gas was used. The size of the laser spot was $300 \times 900 \mu \mathrm{m}$. The plate for the AP-MALDI analysis was a 96-position goldplated steel target. The spectra presented were the averages of 10 scans where one scan was the sum of five microscans for MS and three for $\mathrm{MS}^{2}$. All AP-MALDI experiments were performed in positive ion mode. Pre-activation experiments were performed in $\mathrm{MS}^{2}$ mode with neurotensin 1-11 (NT 111). The precursor ion was set to $m / z 1446$, isolation width $50 \mathrm{Da}$, activation time $300 \mathrm{~ms}$, activation q 0.25 and normalized collision energy 0 or $15 \%$.

\section{Scanning electron microscopy}

A Hitachi S3200N scanning electron microscope (SEM) (Hitachi Ltd., Tokyo, Japan), operated in high-vacuum mode with $3.5 \mathrm{~nm}$ resolution using the secondary electron scintillator detector, was used to collect images of MALDI samples. SEM images were obtained using medium beam current and $20 \mathrm{kV}$ accelerating voltage with $2000 \times$ magnification. Samples were carbon-coated before analysis.

\section{Deposition methods}

\section{Electrospray deposition}

Electrospray sample deposition was performed by pumping sample solution through the electrospray emitter at $100 \mathrm{~nL} /$ min. A potential difference of $1.0-1.4 \mathrm{kV}$ was applied between the syringe pump and the target plate. The target plate was mounted on a grounded motorized XY stage and voltage was applied at the needle of the syringe pump. The distance between the tip and the plate was $100-500 \mu \mathrm{m}$. Each sample spot contained $17 \mathrm{~nL}$ (flow rate $100 \mathrm{~nL} / \mathrm{min}$, dwell time $10 \mathrm{~s}$ ) of sample unless indicated otherwise. Spots began to form after a few seconds of operation, resulting in sample waste estimated to be $<50 \mathrm{~nL}$.

\section{Pull-down deposition}

Pull-down deposition or electric-field-mediated liquid deposition was performed as previously described. ${ }^{9}$ Briefly, sample was pumped through a capillary tube over the MALDI target (2-5 mm capillary-to-plate distance) and a negative potential pulse $(-2 \mathrm{kV}$ for $300 \mathrm{~ms})$ was applied to the MALDI plate to polarize a sample droplet and pull it down to the target plate. The same instrument was used for the pull-down as for the electrospray deposition, except that a flat capillary instead of a tapered one was used. Each sample spot contained $17 \mathrm{~nL}$ sample defined by a flow rate of $100 \mathrm{~nL} / \mathrm{min}$ and dwell time of $10 \mathrm{~s}$.

\section{Dried-droplet deposition}

Dried-droplet deposition was performed by spotting $1 \mu \mathrm{L}$ of sample onto the MALDI target plate using a $10-\mu \mathrm{L}$ micropipette. The resulting droplet was allowed to air dry before analysis.

\section{Sample preparation}

CHCA was recrystallized in ethanol $/ \mathrm{H}_{2} \mathrm{O}(50: 50, \mathrm{v} / \mathrm{v})$ and dissolved in acetonitrile/0.1\% aqueous TFA (50:50, v/v) to yield a stock solution of $10 \mathrm{mg} / \mathrm{mL}$ that was stored at $-80^{\circ} \mathrm{C}$. This stock was diluted with the same solvent to $2.5 \mathrm{mg} / \mathrm{mL}$ before use. The peptides were made up as $1 \mathrm{mg} / \mathrm{mL}$ stock solutions in water, frozen in aliquots, and further diluted in methanol/0.1\% aqueous TFA (50:50, v/v) before use. Peptide solutions were mixed with $2.5 \mathrm{mg} / \mathrm{mL}$ CHCA solution (50:50, v/v) unless indicated otherwise.

\section{Monitoring peptide breakdown in CSF}

Monkey cerebral spinal fluid (CSF), obtained from James Woods' laboratory, was centrifuged at $2000 \mathrm{rpm}$ for $10 \mathrm{~min}$ and the pellet discarded. $40 \mu \mathrm{L}$ of supernatant were removed by pipette and spiked with $4 \mu \mathrm{L}$ of neurotensin (pGluLYENKPRRPYIL) dissolved in water to generate a final concentration of $6.0 \mu \mathrm{M}$. Samples were analyzed before and after incubation in a water bath at $36^{\circ} \mathrm{C}$ for $24 \mathrm{~h}$. For analysis, samples were mixed with $40 \mu \mathrm{L} 0.1 \%$ TFA (all TFA solutions were aqueous) and concentrated and desalted using a Ziptip. The Ziptip was initially wetted by aspirating with acetonitrile/ water (50:50, v/v) twice followed by rinsing with $0.1 \%$ TFA solution twice ( $10 \mu \mathrm{L}$ each rinse). Sample was then aspirated into the tip and dispensed out 7 to 10 times to bind the peptides. The sample on the Ziptip was desalted by aspirating and dispensing to waste $10 \mu \mathrm{L}$ of $0.1 \%$ TFA three times. Peptides were eluted by aspirating and dispensing $10 \mu \mathrm{L}$ of acetonitrile/0.1\% TFA (50:50, v/v) through several cycles into a sample tube. The resulting $10 \mu \mathrm{L}$ peptide sample were diluted four-fold with methanol $/ 0.1 \%$ aqueous TFA (50:50, v/v), and then mixed with $2.5 \mathrm{mg} / \mathrm{mL}$ CHCA $(50: 50, \mathrm{v} / \mathrm{v})$ before deposition onto a MALDI plate by electrospray.

\section{RESULTS AND DISCUSSION}

\section{Electrospray sample deposition conditions}

The objective of this work was to evaluate electrospray for preparation of small sample spots for MALDI. In electrospray deposition, the sample flows through a capillary that is positioned over the MALDI plate such that application of a 
voltage between the capillary and MALDI plate generates a spray of sample onto the surface. Several factors must be considered in determining the best conditions for electrospray sample deposition. The droplet size, $d$, formed by electrospray is given by the following:

$$
d \geq \frac{2 r_{c}^{2} \gamma}{\varepsilon_{0} V_{c}^{2}\left[\ln \left(\frac{4 l}{r_{c}}\right)\right]^{2}}
$$

where $r_{c}$ is the radius of the emitter capillary, $\gamma$ is the surface tension of the solution liquid, $\varepsilon_{0}$ is the permittivity of vacuum, $V_{c}$ is the voltage applied at the emitter tip and $l$ is the distance between the emitter tip and the ground (in this case the MALDI plate). ${ }^{22-24}$ As shown by this expression, for a given solution and emitter tip, increasing $V_{c}$ and $l$ will generate smaller droplet sizes. Droplets erupting from the end of the Taylor cone will evolve into even smaller droplets due to solvent evaporation and Coulomb explosions $^{25}$ before being deposited onto the plate. If the initial droplet size is small enough, it is anticipated that sample will be deposited in a solid form as all the solvent evaporates before reaching the plate. In contrast, sample may be deposited as a solution by increasing the droplet size, which can be achieved by decreasing the spray potential and spray distance.

To determine the effect of controlling droplet size, we examined the effect of electrospray voltage and distance while pumping a 50:50 (v/v) mixture of matrix solution (2.5 mg/mL CHCA) and sample solvent (50:50 (v/v) methanol $/ 0.1 \%$ TFA) at $100 \mathrm{~nL} / \mathrm{min}$. By varying potential and distance we found that samples could be deposited with varying amounts of solvent that resulted in different crystal sizes (see Fig. 2) and analytical performance. For $l=150 \mu \mathrm{m}$ and $V_{c}=1.0 \mathrm{kV}$, samples were deposited as relatively large droplets that built up visibly on the plate as a hemispherical drop. With $l=280 \mu \mathrm{m}$ and $V_{c}=1.1 \mathrm{kV}$, relatively smaller droplets were produced with sample depositing on the MALDI plate as a shallow hemisphere. Using $l=380 \mu \mathrm{m}$ and $V_{c}=1.3 \mathrm{kV}$ resulted in a fine mist that deposited on the surface as a viscous liquid layer with no obvious build up of a hemispherical droplet. Using $l=500 \mu \mathrm{m}$ and $V_{c}=1.4 \mathrm{kV}$, the sample appeared completely dry as it deposited on the plate. We refer to these four conditions as wet spray, damp spray, mist spray and dry spray, respectively. As shown in Fig. 2, wet spray produced $2-4 \mu \mathrm{m}$ sized crystals, damp spray produced $1-2 \mu \mathrm{m}$ sized crystals, mist spray produced crystals of $<1 \mu \mathrm{m}$ diameter, and dry spray resulted in an amorphous layer of sample with no visible crystals formed. For comparison, we found that using the same solution in the pull-down method produced crystals of $3-7 \mu \mathrm{m}$, and the dried-droplet approach produced aggregates of crystals ranging from $15-40 \mu \mathrm{m}$ in diameter.

The effect of these different deposition conditions on the efficiency of matrix volatilization during MALDI was evaluated by exposing samples to multiple laser shots and monitoring the production of the highest peak intensities between $\mathrm{m} / \mathrm{z} 10$ and 600 . These peaks were taken as an indicator of the amount of matrix available on the plate. As shown in Fig. 3(a), matrix signals decreased faster with drier spray conditions. These results demonstrate that smaller crystals desorb faster than larger crystals and therefore are volatized more efficiently, as predicted. ${ }^{17}$ A practical drawback of the highly efficient volatilization of the dry spray and mist spray was the short sample lifetime for limited volume samples.

The effect of the different spray conditions on signal generation was also evaluated. The signal intensity for NT 111 (69 amol/sample) was strongly affected by the electrospray sample deposition such that conditions that produced small or no crystals also produced the weakest signals (see Fig. 3(b)). Possible reasons for the lack of strong signals for the mist and dry spray include poor ionization efficiency or

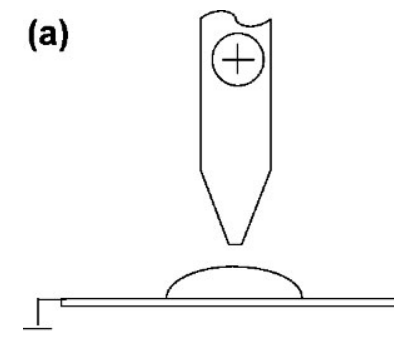

(b)
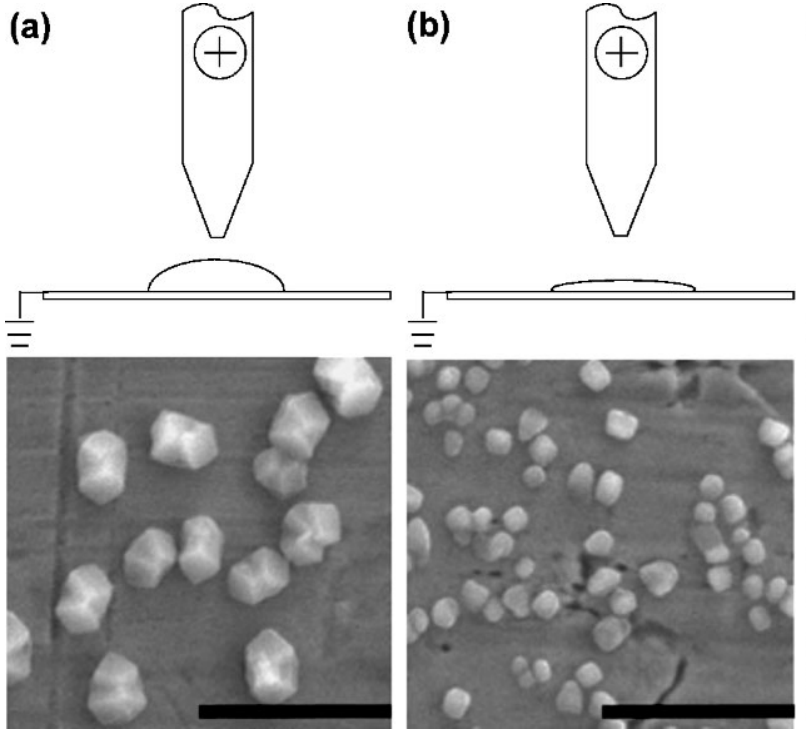

(c)
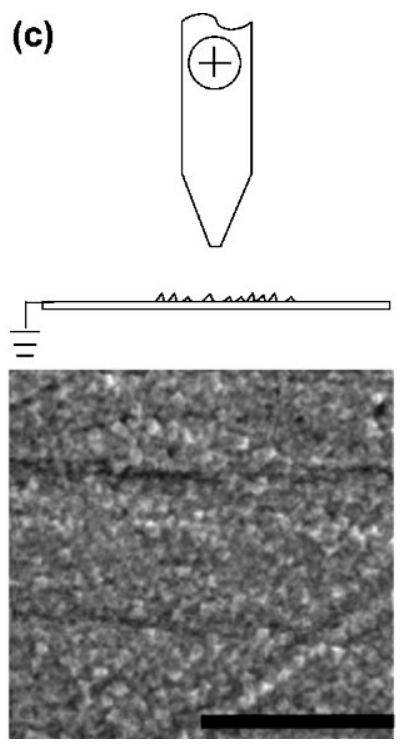

(d)
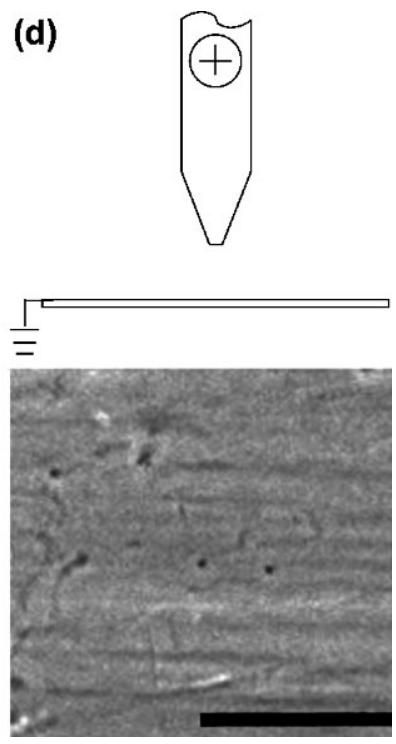

Figure 2. SEM images of sample spots deposited by electrospray onto a stainless steel MALDI plate using four different conditions: (a) wet spray, (b) damp spray, (c) mist spray, and (d) dry spray. Each scale bar corresponds to $10 \mu \mathrm{m}$. Above each SEM image is a side-on depiction of the samples as they appear during deposition for each of the conditions used. 
(a) 1400

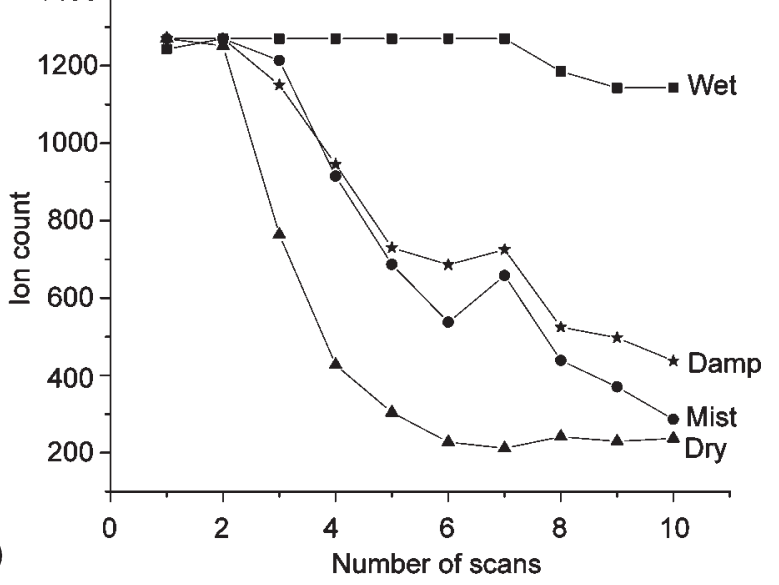

(b)

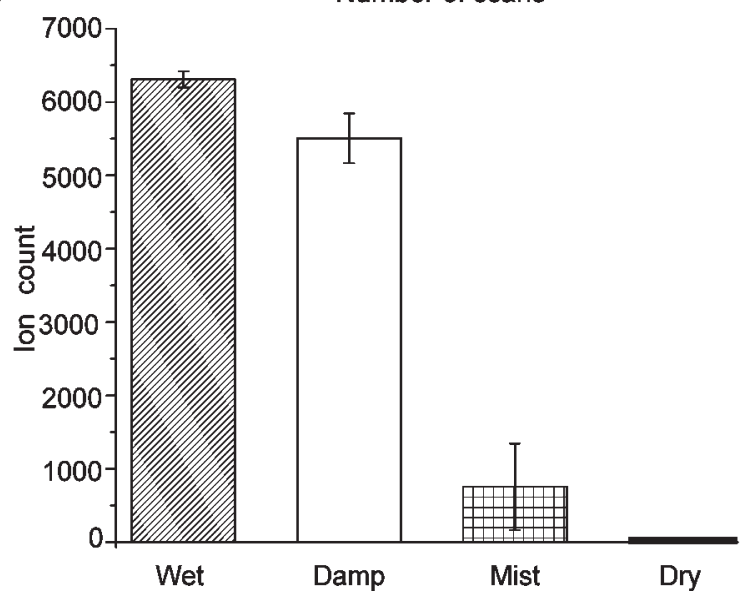

Figure 3. (a) Comparison of lifetimes for $17 \mathrm{~nL}$ samples deposited by different electrospray conditions. The Y-axis represents the average intensity of the highest peak within the range $m / z 10-600(n=5)$. (b) Comparison of average signal intensities for $69 \mathrm{amol}$ of NT $1-11[\mathrm{M}+\mathrm{H}]^{+}$ions under different electrospray conditions $(n=4)$. The error bar corresponds to \pm 1 standard deviation.

inefficient capture of the miniscule crystals formed onto the MALDI plate.

Based on these results, the wet spray condition was used for all further experiments. The exact distance and voltage required to obtain a wet spray varied day-to-day, possibly due to variations in the ambient temperature, humidity, and the geometry of the capillary tip; therefore, $V_{c}$ and $l$ were adjusted to yield the formation of a visible hemispherical droplet on the surface at $100 \mathrm{~nL} / \mathrm{min}$ sample flow rates. The $V_{c}$ and $l$ values required were $0.8-1.2 \mathrm{kV}$ and $100-200 \mu \mathrm{m}$, respectively.

\section{Electrospray sample deposition compared with pull-down and dried-droplet}

The signal-to-noise $(\mathrm{S} / \mathrm{N})$ and reproducibility for detection of a $1.5 \mathrm{nM}$ solution of NT 1-11 by MALDI-TOFMS, and of a 5.0 $\mathrm{nM}$ solution of NT 1-11 by AP-MALDI-QITMS, were obtained for the electrospray, pull-down, and dried-droplet methods (see Table 1). Electrospray deposition samples provided the highest $\mathrm{S} / \mathrm{N}$ on both instruments and the best reproducibility by TOFMS.

One explanation for the improved performance is that the electrospray sample spots $(0.2-0.3 \mathrm{~mm}$ in diameter) were
Table 1. Comparison of $S / N$ and reproducibility for electrospray, pull-down and dried-droplet deposition methods. $S / N$ is the average from six repetitions of depositing the amounts shown

\begin{tabular}{|c|c|c|c|c|c|c|}
\hline \multirow[b]{2}{*}{$\begin{array}{l}\text { Deposition } \\
\text { methods }\end{array}$} & \multicolumn{3}{|c|}{ MALDI-TOF } & \multicolumn{3}{|c|}{ AP/MALDI-QITMS } \\
\hline & $\begin{array}{c}\text { NT1-11 } \\
\text { (amol) }\end{array}$ & $\mathrm{S} / \mathrm{N}$ & $\begin{array}{l}\text { RSD } \\
(\%)\end{array}$ & $\begin{array}{c}\text { NT1-11 } \\
\text { (amol) }\end{array}$ & $\mathrm{S} / \mathrm{N}$ & $\begin{array}{l}\text { RSD } \\
(\%)\end{array}$ \\
\hline Electrospray & 25 & 20 & 27 & 85 & 10 & 39 \\
\hline Pull-down & 25 & 12 & 44 & 85 & 7 & 48 \\
\hline Dried-droplet & 1500 & 7 & 80 & 5000 & 4 & 38 \\
\hline
\end{tabular}

smaller than the pull-down $(0.3 \mathrm{~mm}$ in diameter) and drieddroplet sample spots ( $2 \mathrm{~mm}$ in diameter). As discussed in the introduction, if the sample spot is small enough to match the laser spot in size, then the whole sample can be irradiated simultaneously and therefore sample can be more efficiently used. In our case, the size of the laser spot on the MALDITOFMS instrument was $150 \times 250 \mu \mathrm{m}$ and on the APMALDI-QITMS instrument it was $300 \times 900 \mu \mathrm{m}$.

Improved performance by electrospray sample deposition may also be due to increased homogeneity of resulting sample spots. The small crystals formed by electrosprayed samples tended to be uniformly distributed within the spot. Dried-droplet samples were more heterogeneous in distribution and the formation of crystal aggregates increased size and heterogeneity of crystals. Sample spots formed by pulldown deposition tended to have crystals form along the edge of the spot. In addition, with increasing dwell time, crystals tended to adhere to the outlet of the capillary tip causing sample loss during deposition.

The majority of previous reports describing electrospray sample preparation used higher voltages of $2-8 \mathrm{kV}$ and longer spray distances of $2-4 \mathrm{~cm}$ than what were used here. ${ }^{15-17}$ The new conditions lead to much smaller sample spots than those produced using the larger tip-to-plate distances, thus allowing sample to be used more efficiently and producing detection limits in the attomole range (see below). At the same time, the smaller spot sizes retain the improved relative standard deviation (RSD) previously demonstrated for electrospray sample deposition; however, in our experiments it is unclear whether the improved RSD is due to the smaller spot size or the uniformity of the sample deposition.

While electrospray deposition provided the best $\mathrm{S} / \mathrm{N}$ for both types of instrument used, the $\mathrm{S} / \mathrm{N}$ was significantly worse using the AP-MALDI-QITMS system. It has previously been suggested that $\mathrm{S} / \mathrm{N}$ for MALDI can be enhanced by using a pseudo-MS ${ }^{2}$ experiment in which low-energy collision-induced dissociation is used to reduce the background arising from clusters formed by MALDI. ${ }^{26}$ Using this approach, the S/N could be improved two-fold over those shown in Table 1.

\section{Analytical figures of merit for electrospray sample deposition}

The linearity, sensitivity, and reproducibility of the MALDITOFMS signal for electrospray and dried-droplet samples 
(a)

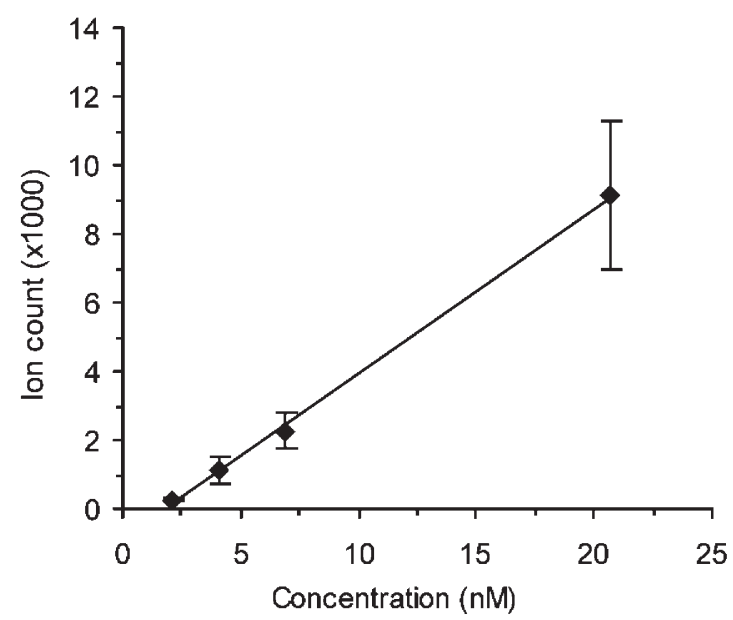

(b)

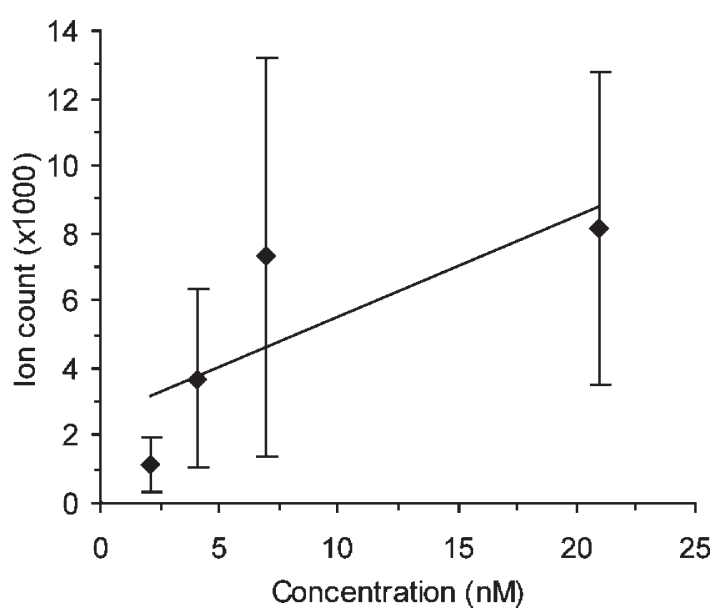

Figure 4. External calibration curves for bradykinin deposited by (a) electrospray and (b) dried-droplet method ( $\mathrm{n}=5$ for each concentration). The error bar corresponds to \pm 1 standard deviation.

were evaluated by preparing external calibration curves for bradykinin samples. As shown in Fig. 4, samples deposited by electrospray had a linear response $\left(R^{2}>0.99\right)$ in the tested range $(35-345 \mathrm{amol})$, whereas poor reproducibility prevented a reasonable linear correlation for the dried-droplet samples $\left(R^{2}=0.63\right)$. The RSD over this range of deposited amounts for electrospray deposition was $10-30 \%$, which was typical for all peptides tested. The calibration curve slope for samples deposited by electrospray ( 480 ion counts/nM) was somewhat higher than that of the samples deposited by the dried-droplet method (300 ion counts/nM), implying greater sensitivity for electrospray deposition. Linear calibration with $R^{2}>0.99$ was also obtained for several other peptides, as summarized in Table 2. LODs for all of these peptides were in the low attomole range. An illustration of the high sensitivity possible with this sample deposition method was demonstrated by the MALDI-TOF spectrum of a $17 \mathrm{~nL}$ sample mixture containing 50 amol each of six neuropeptides, shown in Fig. 5. All of the peptides were detected with $\mathrm{S} / \mathrm{N}>10$.
Table 2. LOD and calibration curves for four $17 \mathrm{~nL}$ neuropeptide samples using electrospray deposition and MALDI-TOFMS. At least four concentrations were used for each curve resulting in the range of amounts shown. Each concentration was repeated five times. $\left(R^{2}\right.$ denotes linear correlation coefficient.)

\begin{tabular}{lcccc}
\hline Peptide & $\begin{array}{c}\text { LOD } \\
\text { (amol) }\end{array}$ & $R^{2}$ & $\begin{array}{c}\text { Slope (ion } \\
\text { counts/amol) }\end{array}$ & $\begin{array}{c}\text { Range } \\
\text { (amol) }\end{array}$ \\
\hline NT1-11 & 10 & 0.998 & 123 & $6-69$ \\
Bombesin & 20 & 0.999 & 99 & $26-103$ \\
[Arg $^{8}$ ]-vasopressin & 0.7 & 0.997 & 440 & $0.8-38$ \\
Bradykinin & 25 & 0.999 & 29 & $35-345$ \\
\hline
\end{tabular}

\section{Sample pre-concentration by electrospray deposition}

An advantage of electrospray deposition is that sample can be continuously deposited into a small area to pre-concentrate dilute samples directly on the MALDI plate. We investigated this possibility by extending the sample deposition time to $350 \mathrm{~s}$ resulting in a deposition of a total volume of $580 \mathrm{~nL}$. The spot size was not affected by the longer deposition time because of the rapid evaporation of solvent as droplets approached the plate; however, the concentration detection limit was improved by 200 -fold. For example, using this condition, spectra with $\mathrm{S} / \mathrm{N}$ of $4 \pm 1(\mathrm{n}=5)$ were obtained for NT $1-11$ at $35 \mathrm{pM}$ (20 amol deposited), as shown in Fig. 6. For pre-concentration it was beneficial to use a lower matrix concentration $(0.125 \mathrm{vs} .1 .25 \mathrm{mg} / \mathrm{mL})$ to reduce chemical noise. The ability to pre-concentrate and analyze dilute

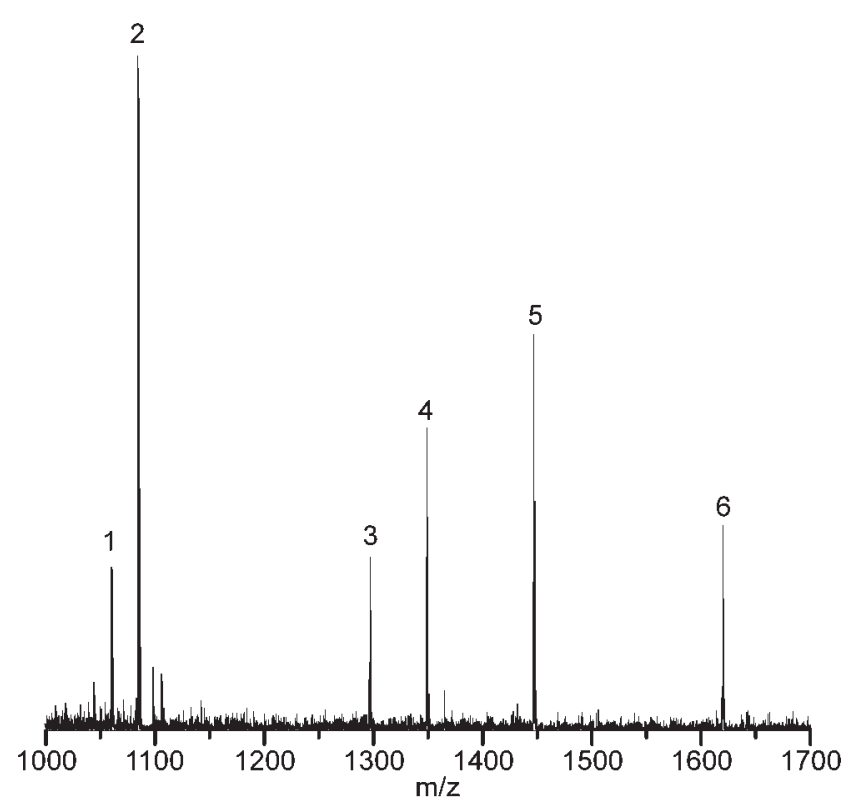

Figure 5. MALDI-TOF mass spectrum of a $17 \mathrm{~nL}$ sample deposited by electrospray that contained $50 \mathrm{amol}$ each of the following peptides: (1) bradykinin ( $\mathrm{m} / \mathrm{z}$ 1060.6), (2) [Arg $\left.{ }^{8}\right]-$ vasopressin ( $m / z$ 1087.4), (3) angiotensin I ( $m / z$ 1296.7), (4) substance $P(m / z 1347.7)$, (5) neurotensin 1-11 ( $m / z$ 1447.8), and (6) bombesin $(\mathrm{m} / z 1620.8)$. The spectrum is a sum of 10 "scans". 


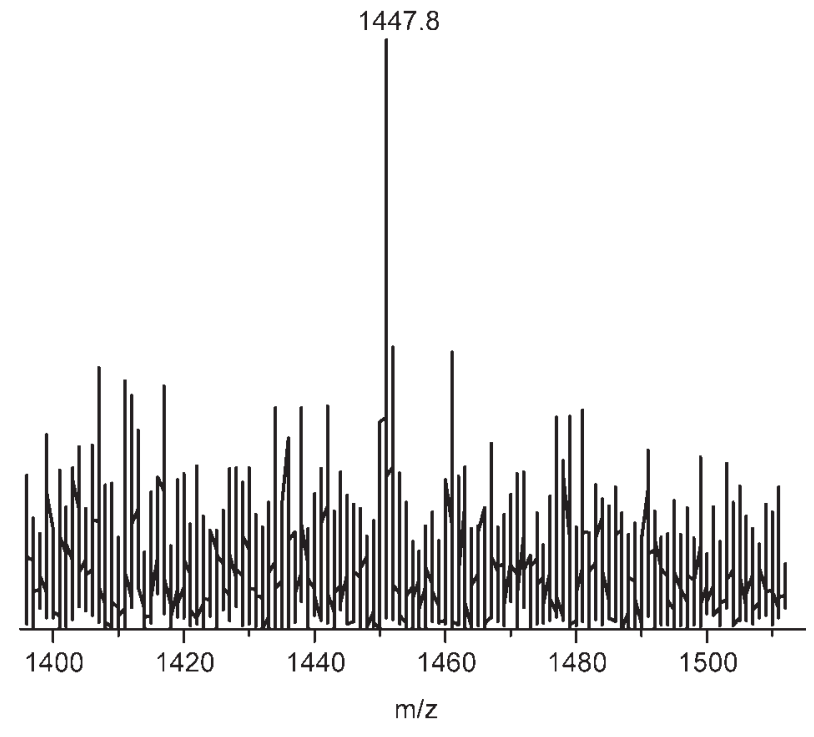

Figure 6. MALDI-TOF mass spectrum of 35 pM NT 1-11 deposited by electrospray over $350 \mathrm{~s}(580 \mathrm{~nL})$. The spectrum is a sum from 10 "scans".

solutions is significant for biological samples where concentration detection limits are often more important than absolute mass detection limits.

\section{Biotransformation of neurotensin in CSF}

In order to demonstrate the utility of electrospray sample deposition for more complex samples, we used this method to determine the degradation products of neurotensin in CSF. Peptide degradation in CSF is a potentially important route for metabolism of hormones, neurotransmitters, and peptidergic drugs. Knowledge of degradation products and the time scale of their appearance is useful in determining the active fragments of peptides as well as their pharmacodynamics. CSF also represents a complex matrix for testing a method as it contains a variety of proteins, peptides, metabolites, and salts. Typical mass spectra of CSF spiked with $6 \mu \mathrm{M}$ neurotensin, obtained before and after $24 \mathrm{~h}$ incubation, are shown in Figs. 7(b) and 7(c) compared with the spectrum for a blank sample, i.e. CSF with no neurotensin added, in Fig. 7(a). For all spectra in Fig. 7, $17 \mathrm{~nL}$ of sample were deposited, corresponding to $40 \mathrm{fmol}$ of neurotensin. After incubation, several new masses are observed including those that correspond to neurotensin fragments 1-12, 1-11, 1-10 and 1-8. These results indicate that a significant degradation path for neurotensin in CSF is by cleavage at the C-terminus, an action likely mediated by a carboxypeptidase.

\section{CONCLUSIONS}

Electrospray sample deposition for MALDI is demonstrated to yield low attomole detection limits for peptides, and RSDs of $10-30 \%$ for a variety of peptides in the 10-500 amol range. The method was demonstrated for analysis of the biotransformation of neurotensin in CSF. The excellent detection limits and good reproducibility are attributed to producing a small, relatively homogeneous sample spot $(<300 \mu \mathrm{m}$ in diameter) with crystallite size of a few micrometer diameter. By (a)

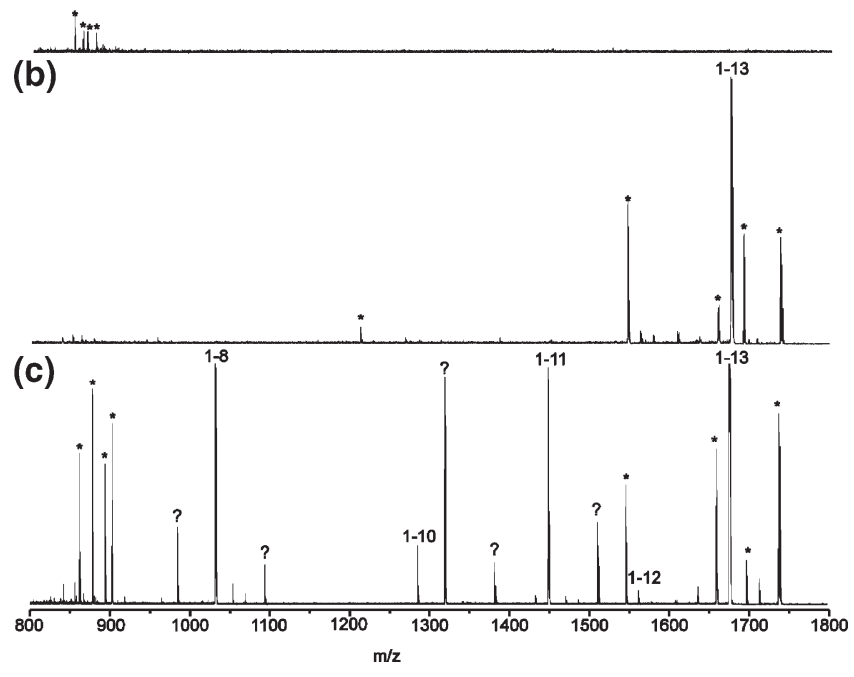

Figure 7. MALDI-TOF mass spectra of (a) CSF blank, (b) neurotensin $(40 \mathrm{fmol})$ in CSF without incubation, and (c) neurotensin $(40 \mathrm{fmol})$ in CSF after $24 \mathrm{~h}$ incubation. Peaks marked with ? and * are due to unknowns and impurities, respectively. 20 "scans" were added to obtain each spectrum.

continuously delivering sample to the same spot, electrospray deposition can also pre-concentrate samples enabling low pM detection limits. The good performance of the electrospray method requires that sample is deposited with some solvent as overly dry deposition results in small or no crystals that are efficiently volatilized but produce weak signals or are inefficiently captured on the target plate. The wet electrospray method is in principle similar to the pull-down method, and the experiments where direct comparisons were made reveal similar results with a slight sensitivity advantage to electrospray (Table 1). The slightly more complicated design for electrospray deposition (i.e., it requires a pulled tip) may negate its apparent sensitivity advantage; however, it is unknown at this time how the pull-down method would compare with electrospray deposition with respect to other figures of merit and for pre-concentration experiments.

While mass detection limits reported here refer to sample consumed, it is apparent that the present system requires somewhat more sample (approximately $285 \mathrm{~nL}$ to load capillaries) to generate $17 \mathrm{~nL}$ sample spots. This volume could be reduced by using smaller bore tubing, filling just a portion of the capillary with sample (either from the tip or the back), or using a microfluidic system to manipulate the samples. The efficiency based on sample used can also be increased by taking advantage of the pre-concentrating effect since the larger volumes utilized in pre-concentration are more easily manipulated. In addition, the method is, in principle, compatible with coupling to microscale separation techniques like capillary liquid chromatography because of the compatibility with continuous sample deposition and low flow rate, where the inherent mass sensitivity of the approach could be readily utilized to full advantage. 


\section{Acknowledgements}

This work was supported by NIH (NS 38476) and the Wenner-Gren Foundations (K.N.). The scanning electron microscope used in this study was funded in part by National Science Foundation Grant EAR-9628196.

\section{REFERENCES}

1. Karas M, Hillenkamp F. Anal. Chem. 1988; 60: 2299.

2. Gobom J, Nordhoff E, Mirgorodskaya E, Ekman R, Roepstorff P. J. Mass Spectrom. 1999; 34: 105.

3. Vorm O, Mann M. J. Am. Soc. Mass Spectrom. 1994; 5: 955.

4. Jespersen S, Niessen WMA, Tjaden UR, Vandergreef J, Litborn E, Lindberg U, Roeraade J. Rapid Commun. Mass Spectrom. 1994; 8: 581 .

5. Schuerenberg M, Luebbert C, Eickhoff H, Kalkum M, Lehrach H, Nordhoff E. Anal. Chem. 2000; 72: 3436.

6. Moyer SC, Budnik BA, Pittman JL, Costello CE, O'Connor PB. Anal. Chem. 2003; 75: 6449.

7. Keller BO, Li L. J. Am. Soc. Mass Spectrom. 2001; 12: 1055.

8. Miliotis T, Kjellström S, Nilsson J, Laurell T, Edholm LE, Marko-Varga G. J. Mass Spectrom. 2000; 35: 369.

9. Ericson C, Phung QT, Horn DM, Peters EC, Fitchett JR, Ficarro SB, Salomon AR, Brill LM, Brock A. Anal. Chem. 2003; 75: 2309.

10. Zhang H, Caprioli RM. J. Mass Spectrom. 1996; 31: 1039.

11. Preisler J, Foret F, Karger BL. Anal. Chem. 1998; 70: 5278.
12. Wall DB, Berger SJ, Finch JW, Cohen SA, Richardson K, Chapman R, Drabble D, Brown J, Gostick D. Electrophoresis 2002; 23: 3193.

13. Zhang B, McDonald C, Li L. Anal. Chem. 2004; 76: 992.

14. Yao J, Scott JR, Young MK, Wilkins CL. J. Am. Soc. Mass Spectrom. 1998; 9: 805.

15. Hensel RR, King RC, Owens KG. Rapid Commun. Mass Spectrom. 1997; 11: 1785

16. Axelsson J, Hoberg A-M, Waterson C, Myatt P, Shield GI, Varney J, Haddleton DM, Derrick PJ. Rapid Commun. Mass Spectrom. 1997; 11: 209.

17. Sadeghi M, Vertes A. Appl. Surf. Sci. 1998; 127-127: 226.

18. Go EP, Prenni JE, Wei J, Jones A, Hall SC, Witkowska HE, Shen Z, Siuzdak G. Anal. Chem. 2003; 75: 2504.

19. Hanton SD, Hyder IZ, Stets JR, Owens KG, Blair WR, Guttman CM, Giuseppetti AA. J. Am. Soc. Mass Spectrom. 2004; 15: 168.

20. Caprioli RM, Farmer TB, Gile J. Anal. Chem. 1997; 69: 4751.

21. Mowthorpe S, Clench MR, Cricelius A, Richards DS Parr V, Tetler LW. Rapid Commun. Mass Spectrom. 1999; 13: 264.

22. Juraschek R, Dulcks T, Karas M. J. Am. Soc. Mass Spectrom. 1999; 10: 300.

23. Juraschek R, Röllgen FW. Int. J. Mass Spectrom. 1998; 177: 1.

24. Loeb L, Kip A, Hudson G, Bennett W. Phys. Rev. 1941; 60: 714.

25. Fenn JB, Mann M, Meng CK, Wong SF, Whitehouse CM. Science 1989; 246: 64.

26. Krutchinsky AN, Chait BT. J. Am. Soc. Mass Spectrom. 2002; 13: 129. 